\title{
Characterization of Thermochemically Surface-Hardened Titanium by Light Optical Microscopy
}

Gammeltoft-Hansen, Niklas; Munch, Steffen S.; Jellesen, Morten Stendahl; Somers, Marcel A. J.; Christiansen, Thomas Lundin

Published in:

Materials Performance and Characterization

Link to article, DOI:

10.1520/MPC20160083

Publication date:

2017

Document Version

Peer reviewed version

Link back to DTU Orbit

Citation (APA):

Gammeltoft-Hansen, N., Munch, S. S., Jellesen, M. S., Somers, M. A. J., \& Christiansen, T. L. (2017).

Characterization of Thermochemically Surface-Hardened Titanium by Light Optical Microscopy. Materials Performance and Characterization, 6(3). https://doi.org/10.1520/MPC20160083

\section{General rights}

Copyright and moral rights for the publications made accessible in the public portal are retained by the authors and/or other copyright owners and it is a condition of accessing publications that users recognise and abide by the legal requirements associated with these rights.

- Users may download and print one copy of any publication from the public portal for the purpose of private study or research.

- You may not further distribute the material or use it for any profit-making activity or commercial gain

- You may freely distribute the URL identifying the publication in the public portal 


\title{
Characterization of thermochemically surface hardened titanium
}

\section{by light optical microscopy}

\author{
Niklas Gammeltoft-Hansen, Steffen S. Munch, Morten S. Jellesen,
}

\author{
Marcel A.J. Somers, Thomas L. Christiansen*
}

Technical University of Denmark, Department of Mechanical Engineering, Produktionstorvet b.425, DK 2800 Kgs. Lyngby, Denmark

*Corresponding author

Keywords Titanium; Surface hardening; Mixed interstitial compound; Mixed interstitial solid solution; Oxidation; Carbo-oxidation; Metallography

\begin{abstract}
Thermochemically treated titanium grade 2 and 5 were investigated by light optical microscopy and hardness indentation. Gaseous oxidation in oxygen and $\mathrm{N}_{2} \mathrm{O}$ containing atmospheres resulted in a diffusion zone of oxygen in solid solution in titanium with a hardness up to $1000 \mathrm{HV}$. A surface scale consisting of oxide can be present depending on the treatment conditions. A new type of carbo-oxidation treatment was applied, where carbon and oxygen are simultaneously incorporated into the surface. This resulted in new microstructural features such as a deep zone of mixed interstitial solid solution, i.e. a diffusion zone, and surface regions consisting of a mixed interstitial compound ( $\mathrm{TiC}_{\mathrm{X}} \mathrm{O}_{1-\mathrm{X}}$ structure). Carbo-oxidation yields hardness values in excess of $2500 \mathrm{HV}$ in the mixed interstitial compound and values up to $1500 \mathrm{HV}$ in the diffusion zone. Simultaneously, with the surface hardening treatment, core hardening of the material can be obtained.
\end{abstract}




\section{Introduction}

Titanium and its alloys are used in applications where high specific strength and light weight are required, e.g. hardenable Ti alloys are widely applied in aerospace industry. Titanium is also known for its favorable corrosion properties, which are superior to most iron-based alloys and it is the material of choice for applications where high corrosion performance is required, e.g. off-shore, chemical industries etc. The favorable corrosion performance of titanium is a result of its ability to spontaneously form a strongly adherent surface oxide layer (self-passivation). Another aspect of titanium is its biocompatibility, making it the ideal choice for biomedical applications such as implants. However, titanium suffers from poor tribological properties making it unapt for applications where wear is experienced. The poor wear behavior strongly curtails more widespread use of this otherwise highly attractive engineering material. Surface hardening is one route to remedy this inherent problem of titanium

\subsection{Surface hardening of titanium}

Surface hardening of titanium is somewhat special due the presence of the strongly adherent impenetrable oxide layer and that the element itself is a very strong nitride and carbide former. For this reason $\mathrm{Ti}$ is also extensively used as an alloying element in iron-based alloys. The impenetrability and strong affinity of the material itself to interstitials effectively excludes the use of conventional surface hardening methods for incorporation of nitrogen and/or carbon. In fact, the interstitial elements nitrogen, carbon and oxygen, are usually considered as impurity elements in Ti alloys. In order to circumvent the major problem with the passive layer barrier, relatively high temperatures are required and special processes have to be applied. A general overview of surface hardening methods based on oxygen, carbon, nitrogen and boron is given in references [1,2]. 
Gaseous nitriding at high temperature (e.g. $\left.1000^{\circ} \mathrm{C}\right)$ is the "classical" way to surface harden titanium; exposing titanium to high purity molecular nitrogen gas at temperatures above, say $800^{\circ} \mathrm{C}$, results in formation of $\mathrm{TiN}$ and $\mathrm{Ti}_{2} \mathrm{~N}$ nitride and a (supporting) diffusion zone with varying thickness [e.g. 3, 4, 5, 6]. The resulting surface layer of TiN has a golden color and will aesthetically change the appearance of the treated $\mathrm{Ti}$, but will result in high hardness and low friction coefficient. More recently, attempts have been made to control the nitrogen-containing atmosphere to develop exclusively a nitrogen diffusion zone by applying a very low partial pressure of $\mathrm{N}_{2}$ to avoid formation of Ti-nitrides [7]. There is limited work in the literature on carburizing of titanium $[8,9,10,11,12]$. Carburizing is carried out at high temperature in a carbon bearing gas (e.g. $\left.\mathrm{CH}_{4}\right)$ and this transforms the surface into very hard cubic $\mathrm{Ti}_{1-\mathrm{x}} \mathrm{C}$ carbide. The solubility of carbon in titanium is low, which means that essentially no diffusion zone forms below the hard $\mathrm{Ti}_{1-\mathrm{x}} \mathrm{C}$ carbide. Hence carburizing results in a hard (thin) layer on a relatively soft substrate, which is typically unwanted due to risk of an egg-shell effect. Oxidation is generally considered as a detrimental high temperature corrosion mechanism, but in the case of titanium oxygen can - counterintuitively - be used for surface hardening. Titanium has a large capacity for oxygen in solid solution (32.4 at.\%) and can form several types of oxides, e.g. rutile and anatase, $\mathrm{TiO}_{2}$. In the 1960 s oxidation of titanium and surface hardening with oxygen were investigated [13,14] and later also (sporadically) in different media, pressure- and temperature ranges [e.g. 15,16,17,18,19,20]. The oxygen-titanium system enables relatively thick diffusion zones due to the high solid solubility. A plethora of (mainly unsystematic) work on energy-assisted (plasma/ion-based) methods for incorporation of interstitials can also be found in the literature [e.g. 21,22,23 24,25]. The main benefit of such methods is the possibility to apply lower temperatures as sputtering is an integrated part of the method which effectively removes the barrier oxide layer. 
So-called mixed interstitial compounds and solid solutions based on the ternary systems N-C-Ti, NO-Ti, C-O-Ti are claimed to have interesting properties. These systems (viz. N-C-Ti) are also widely used for coatings by PVD/CVD methods. Thermochemical treatment applying two interstitials have been suggested to hold promise by Fedirko et al. due to the favorable properties that can be obtained [26,27]. The Ti system is particularly interesting as substitution of interstitial elements is possible between the oxides, nitrides and carbides; i.e. formation of a broad range of mixed-interstitial compounds or solid solutions [28]. The mixed-interstitial compounds and solid solutions have physicochemical properties significantly different from those of the binary compounds and solutions. The ternary compounds have higher hardness, wear resistance, corrosion resistance, thermal resistance and radiation resistance than the binary compounds [26]. In a recent publication on (largely uncontrolled) pack cementation treatment, which essentially is a gas process, Bailey and Sun showed that a network layer of TiC could be formed on top of a $\mathrm{Ti}(\mathrm{O})$ diffusion zone [29]. It was suggested that this (favorable) combination was the consequence of air oxidation during heating and subsequent formation of $\mathrm{CO}$ for carburizing at high temperature.

The present contribution shows the possibility for applying purely gaseous processes for controlled oxidation and transformation of the surface into mixed-interstitial solid solution and compound. It is not the intention to provide a systematic treatise of such processes but to showcase the possibilities of new (mixed-)interstitial gaseous surface hardening methods. Simultaneously with these treatments, core hardening can be achieved. In the following this is illustrated for titanium grade 2 and 5 by means of light optical microscopy methods.

\section{Experimental}

\subsection{Materials}


Titanium grade 2 and 5 were applied for the investigations and the nominal compositions of the materials are given in Table 1 . Titanium grade $5(\mathrm{Ti6A} 14 \mathrm{~V})$ is an $\alpha / \beta$ alloy which typically is heat treated to obtain higher strength.

\subsection{Gaseous surface hardening}

Ambient air oxidation was carried out in a Nabertherm open box furnace. Atmosphere controlled $\mathrm{O}_{2}$-Ar oxidation was carried out in an Entech furnace equipped with a Kanthal tube fitted with Brooks electronic mass-flow controllers. The total gas flow rate was $200 \mathrm{ml} / \mathrm{min}$.

Carbo-oxidation was performed in a Netzsch thermal analyzer STA 449F1 in a carbon and oxygen providing atmosphere; the process is presently proprietary. The heating rate to process temperature was $20 \mathrm{~K} / \mathrm{min}$ and the cooling rate was $50 \mathrm{~K} / \mathrm{min}$. The applied process temperatures were $1000^{\circ} \mathrm{C}$ and $1050^{\circ} \mathrm{C} . \mathrm{N}_{2} \mathrm{O}$ oxidation was also performed in the Netzsch thermal analyzer; total flow was 60 $\mathrm{ml} / \mathrm{min}$. Details about oxidation and carbo-oxidation treatments are provided in the figure captions.

\subsection{Metallography}

All treated samples were cut with a Struers precision Accutome. The cross sections were prepared by hot mounting in a Struers Prontopress 20 using Durofast resin. Preheating at $180^{\circ} \mathrm{C}$ for 5 minutes; holding time 6 min with $20 \mathrm{kN}$ pressure and slow cooling ( $8 \mathrm{~min}$ ). The embedded samples were prepared using a Struers Rotoforce 4 with Rotopol 22. The grinding and polishing procedure is given in table 2 .

Etching was performed using Keller's reagent $(185 \mathrm{ml}$ distilled water $+5 \mathrm{ml}$ nitric acid $65 \%+3 \mathrm{ml}$ hydrochloric acid 32\% + $4 \mathrm{ml}$ hydrofluoric 10\%) for an etching time from 10 and 40 seconds, depending on the effect of the thermochemical treatment (microstructural features present). 
Optical microscopy was performed on the cross sections using a Zeiss Neophot 32 reflected light microscope. Microhardness was measured using a Future Tech model FM-700 hardness tester on the mounted cross sections applying a load of $25 \mathrm{gf}$ and a dwell time of $10 \mathrm{~s}$.

\section{Results and discussion}

\subsection{Oxidation}

Microstructures of oxidized titanium grade 2 are shown in Fig.1. Different treatments have been applied to illustrate the response of the material. Fig.1a depicts the microstructure after oxidation in a controlled $\mathrm{O}_{2}-\mathrm{Ar}$ atmosphere at $750^{\circ} \mathrm{C}$ for 2 hours, combined with a post heat treatment for core hardening. At $750^{\circ} \mathrm{C}$ the high content of $\mathrm{O}_{2}$ results in a fast development of a rutile $\mathrm{TiO}_{2}$ scale and a shallow diffusion zone (not shown). The applied temperature of $750^{\circ} \mathrm{C}$ is below the beta-transus temperature and no transformation occurs in the sample, neither in the case nor in the core. Upon heat treatment at $970^{\circ} \mathrm{C}$ in ambient air the rutile layer is partly dissolved and the oxygen content in the surface is further augmented. The temperature $970^{\circ} \mathrm{C}$ is above beta transus for the material and the core is therefore fully transformed into b.c.c. $\beta$-Ti, while the oxygen-rich case remains h.c.p. $\alpha$ $\mathrm{Ti}$, as oxygen, in solid solution, is a strong alpha stabilizer. Final quenching in water has the consequence that the core is transformed into h.c.p. $\alpha$ '-martensite, possibly with some retained $\beta$ Ti. The oxide scale (viz. rutile $\mathrm{TiO}_{2}$ ) present at $970^{\circ} \mathrm{C}$ spalls off during the quench treatment and leaves only the diffusion zone. The hardness of the core after quenching is $267( \pm 17) \mathrm{HV}$ compared to $202( \pm 33) \mathrm{HV}$ for the delivered equiaxed condition. For low-alloyed Ti the maximum strength and hardness is obtained after quenching; tempering/ageing has a larger effect for alloyed Ti. The hardness of the case having an oxygen solid solution is $1050 \mathrm{HV}$ at the surface. In Fig. $1 \mathrm{~B}$ a comparable microstructure is observed, but the diffusion zone of oxygen is significantly thicker. 
The treatment has been carried out solely in atmospheric air and was followed by direct quenching in water from the treatment temperature. A treatment temperature of $910^{\circ} \mathrm{C}$ is slightly above the beta transus and the core has transformed into martensite. The alpha-stabilized case (oxygen) clearly exhibits relatively large grains due to grain growth of the original alpha structure. The chemical nature of oxygen in solid solution is also evident; the etching response varies over the thickness of the diffusion zone, thus revealing a gradient in the dissolved oxygen content. The nearsurface region of the oxygen-rich case appears unaffected by Keller's reagent, indicating improved corrosion resistance. The core microstructure shown in Fig. 1C is equivalent to the structure (and heat treatment) from Fig. 1A, except for a final aging treatment of the martensite, i.e. $600^{\circ} \mathrm{C}$ for two hours. For low alloyed Ti (as Grade 2) the strength/hardness is only marginally affected. However, some refinement of the martensite morphology is observed, i.e. more distinct packets and lamellas.

The microstructure shown in Fig. 1D is the result of a relatively long treatment at $1000^{\circ} \mathrm{C}(20$ hours) in an atmosphere containing $\mathrm{N}_{2} \mathrm{O} . \mathrm{N}_{2} \mathrm{O}$ is a very potent oxidizer similar to $\mathrm{H}_{2} \mathrm{O}_{2}$ (at lower temperatures). Indeed a thick oxide layer together with a thick diffusion zone is obtained. The core is transformed into a Widmanstätten structure, i.e. plates of $\alpha$. The outer oxide layer has a layered morphology but no spallation is observed. The visual appearance of the treated sample was a milkywhite surface which had swollen (clear change of dimensions). X-ray diffraction of the outermost surface of the oxide scale (not included) confirmed the presence of rutile $\mathrm{TiO}_{2}$. The thick underlying diffusion zone is a consequence of the high temperature and long treatment time. Hardness values in excess of $1000 \mathrm{HV}$ were obtained in this zone. Massive grain growth is observed within the alphastabilized oxygen-rich case. Obviously, this treatment has no practical applicability but illustrates the behavior of $\mathrm{Ti}$ in a highly oxidizing atmosphere.

\subsection{Carbo-oxidation}


Carbo-oxidation as surface hardening treatment entails simultaneous incorporation of oxygen and carbon into the surface of the titanium. This can result in mixed-interstitial solid solutions or compounds (based on $\mathrm{O}$ and $\mathrm{C}$ ), cf. the introduction. Fig. 2 depicts carbo-oxidation at $1000^{\circ} \mathrm{C}$ for 20 hours of Ti grade 2 . The case consists of a mixed-interstitial solid solution zone (diffusion zone) and a mixed interstitial compound. The mixed interstitial compound phase is located preferentially along grain boundaries in the diffusion zone and as a relatively thin layer at the surface (cf. Fig. 2C). X-ray diffraction analysis (not included) revealed that the mixed interstitial compound is the cubic (B1) $\mathrm{TiC}_{\mathrm{X}} \mathrm{O}_{1-\mathrm{X}}$ structure. The hardness of the mixed interstitial compound phase is in average $1819( \pm 235) \mathrm{HV}$ and the diffusion zone is up to $1148 \mathrm{HV}$. The morphology of the mixed-interstitial compound exhibits local gradients (cf. Fig 2C) and the center-line contains porosities or alternatively graphite precipitates (presently not confirmed). The overall layer thickness is approximately $400 \mu \mathrm{m}$, which is much larger than for single element hardening and strongly suggests a synergistic effect of dissolving two interstitials. The case can be considered a composite consisting of hard mixed interstitial compound phase ( $\mathrm{TiC}_{\mathrm{X}} \mathrm{O}_{1-\mathrm{X}}$ type) embedded in a 'softer' diffusion zone. Indeed, preliminary results on wear in a tribometer using a pin on disc setup with an alumina counterpart (not shown) show very high wear resistance of the surface hardened Ti. Moreover corrosion testing (exposure in a solution containing $0.25 \mathrm{wt} . \%$ hydrofluoric acid adjusted to $\mathrm{pH}=1$ with hydrochloric acid) showed that surface hardened $\mathrm{Ti}$, similar to the treatment shown in Fig. 2, was inert even after 16 days exposure; the untreated Ti reference corroded immediately upon contact with the electrolyte.

The core of the surface hardened material is shown in Fig.3 and exhibits a Widmanstätten morphology (cf. above). The plates of alpha formed in the original beta structure are clearly seen. This results in a hardness increase compared to an equiaxed structure of alpha grains in the asdelivered condition. 
A similar treatment, but at $1050^{\circ} \mathrm{C}$, is shown in Fig. 4. Fig. 4a shows a macroscopic image (stereomicroscope) of the treated component. A uniform case of almost one mm is obtained both internally and externally. Clearly, the higher temperature results in faster growth. Figs. 4b to 4e show the morphology of the hard case at different magnifications. The same features in the mixedinterstitial compound as observed at $1000^{\circ} \mathrm{C}$ are visible, i.e. signs of porosity or graphite precipitation (Fig. 4E). It is clear that the mixed interstitial compound phase forms a network; at this temperature it is not fully clear if this is associated with the alpha grain boundaries. A hardness depth profile of the surface hardened zone is depicted in Fig.5. The figure contains two profiles: a profile obtained for the diffusion zone and one for the mixed-interstitial compound. The hardness of the mixed-interstitial compound phase is in the range 1700 to $3000 \mathrm{HV}$ with an average around $2200 \mathrm{HV}$ in the surface region which is significantly harder than the values obtained at $1000^{\circ} \mathrm{C}$. This could indicate that more carbon is incorporated in the $\mathrm{TiC}_{\mathrm{X}} \mathrm{O}_{1-\mathrm{X}}$ structure. The large scatter of measured hardness values can be attributed to local hardness (composition) gradients in the mixed interstitial compound; here it also has to be emphasized that the values are obtained in a heterogeneous (3-dimensional) structure where measurement can be affected by adjacent (harder/softer) structures. The diffusion zone is generally harder than at $1000^{\circ} \mathrm{C}$; a maximum of about $1500 \mathrm{HV}$ is obtained at a depth of $200 \mu \mathrm{m}$. The hardness drops slightly towards the surface but is compensated by a larger fraction of mixed-interstitial compound phase with a significantly higher hardness.

A feature which is evident is the incipient tendency for horizontal cracks in the diffusion zone (Fig. 4B). This is not surprising due to the very deep case depth achieved; certainly 20 hours at this treatment temperature is too much. The parallel and horizontal cracks suggest compressive surface stresses, which can be a combination of growth and thermal stresses. 
In Fig. 6 surface hardened Ti alloy grade 5 is shown. The treatment temperature was $1000^{\circ} \mathrm{C}$ similar to Fig. 2 and 3. Clearly, the response of this alloys compared to (unalloyed) grade 2 is markedly different. In the near surface region a uniform layer can be observed, which is approximately $20 \mu \mathrm{m}$ thick with a hardness of $1416 \mathrm{HV}$; this is most likely $\mathrm{TiC}_{\mathrm{X}} \mathrm{O}_{1-\mathrm{X}}$ rich in oxygen. Below this compound an approximately $100 \mu \mathrm{m}$ thick diffusion zone extends and gradually fades into the core microstructure. This zone can be described as mainly oxygen-stabilized alpha. The presence of aluminum, also being a strong oxide former, is attributed to be responsible for the different response of the material. Preferential and fast formation of alumina $\left(\mathrm{Al}_{2} \mathrm{O}_{3}\right)$ either as (dispersed) internal oxidation or as a thin surface zone can impede further growth. Al has a lower affinity to oxygen than $\mathrm{Ti}$, but expectedly has a higher mobility than Ti in the alloy. Furthermore, the solubility product of $\mathrm{Al}_{2} \mathrm{O}_{3}$ is much lower than for $\mathrm{TiO}_{2}$. Hence it is expected that $\mathrm{Al}$ rich oxide is located at the surface where the oxygen pressure imposed by the gas atmosphere is highest. Indeed, for pure oxidation experiments the surface zone was rich in Al, as identified with EDS analysis (not shown). For the carbo-oxidation treatment the same behavior is expected and $\mathrm{Al}$ enrichment in the surface would impede fast ingress of carbon and oxygen. In this respect it should also be mentioned that $\mathrm{Al}$ does not form carbides. The role of vanadium, if any, is presently not clear. The core microstructure after cooling from $1000^{\circ} \mathrm{C}(50 \mathrm{~K} / \mathrm{min})$ can be described as equiaxed primary alpha grains surrounded by (partly) transformed beta regions (acicular alpha in beta). This suggests that the material was treated in the two phase alpha-beta region (at $1000^{\circ} \mathrm{C}$ ) prior to cooling.

\subsection{Metallography and surface hardening of titanium.}

Revealing microstructures in titanium alloys is not an easy task due to the superior corrosion resistance of these materials. This implies that relatively aggressive reagents have to be applied. The task is further complicated for surface hardened components where the surface region has a 
different etching response than the core. For the present examples the incorporation of oxygen and carbon markedly changed the chemical behavior of the interstitial-rich part of the material.

The shown carbo-oxidation gaseous treatments appear highly effective in achieving deep hard cases on titanium (viz. unalloyed grade). This can be attributed to the synergistic effect of the two interstitial elements with respect to solubility and fast growth kinetics of mixed interstitial solid solutions and compounds. These topics are presently largely uninvestigated and will be addressed in future work.

\section{Conclusions}

Gaseous surface hardening of titanium grade 2 and 5 is possible by applying controlled oxidation or carbo-oxidation. Oxidation can result in a solid solution of oxygen in titanium which provides a strengthening effect. Hardness values up to $1000 \mathrm{HV}$ can be achieved. A new gaseous carbooxidation process enables very thick hard cases on titanium consisting of a diffusion zone with a hardness of more than $1200 \mathrm{HV}$ and a mixed interstitial compound zone with a hardness value of more than $2500 \mathrm{HV}$. Case depths up to $1 \mathrm{~mm}$ can be obtained which imparts the treated surfaces with high wear and corrosion resistance. Different microstructural features (core and case) can be revealed by use of the metallographic procedures applied. 
$\underline{\text { Tables: }}$

Table 1. Nominal composition of ASTM Ti grade 2 and 5 (wt $\%$ ).

\begin{tabular}{|c|c|c|c|c|c|c|c|c|}
\hline Grade & $\mathbf{T i}$ & Al & $\mathbf{V}$ & $\mathrm{C}$ & $\mathbf{F e}$ & $\mathbf{H}$ & $\mathbf{N}$ & $\mathbf{O}$ \\
\hline 2 & 99.2 & - & - & Max. 0.1 & Max. 0.3 & $\begin{array}{l}\text { Max. } \\
0.015\end{array}$ & Max. 0.03 & Max. 0.25 \\
\hline $\begin{array}{l}5 \\
\text { (Ti6Al4V) }\end{array}$ & 90 & 6 & 4 & - & Max. 0.25 & - & - & Max. 0.2 \\
\hline
\end{tabular}

Table 2. Metallographic preparation of titanium

\begin{tabular}{|l|l|l|l|}
\hline Step & Grinding/polishing & Time [min] & Pressure (per sample) [N] \\
\hline 1 & 500 \# paper & 2.5 & 10 \\
\hline 2 & 1000 \# paper & 2.5 & 10 \\
\hline 3 & 4000 \# paper & 2.5 & 10 \\
\hline 4 & $\begin{array}{l}\text { Mol 3 } \mu \mathrm{m} \text { diamond } \\
\text { suspension }\end{array}$ & 3 & 10 \\
\hline 5 & Nap 1 $\mu \mathrm{m}$ diamond & 3 & 10 \\
\hline 6 & suspension & & 10 \\
\hline
\end{tabular}

Figure captions:

Fig. 1. Ti grade 2. A) oxidation in $50 \mathrm{vol} \% \mathrm{O}_{2}$ at $750^{\circ} \mathrm{C}$ ( 2 hours) followed by slow cooling; then post heat treated at $970^{\circ} \mathrm{C}$ for $20 \mathrm{~min}$. (air) and quenched in water. B) Oxidation in open air furnace (air) at $910^{\circ} \mathrm{C}$ for 2 hours and directly quenched in water. C) Core microstructure after heat treatment at $970^{\circ} \mathrm{C}$ for $20 \mathrm{~min}$. and quenched in water (cf. A); then aged at $600^{\circ} \mathrm{C}$ for 2 hours. D) 
Oxidation in $83 \% \mathrm{~N}_{2} \mathrm{O}-17 \% \mathrm{Ar}$ gas mixture at $1000^{\circ} \mathrm{C}$ for 20 hours followed by rapid cooling $(50 \mathrm{~K} / \mathrm{min})$.

Fig. 2. Ti grade 2 . Carbo-oxidation at $1000^{\circ} \mathrm{C}$ for 20 hours. This results in formation of a case consisting of a mixed interstitial compound and diffusion zone. Different magnifications are shown.

Fig. 3. Ti Grade 2 core microstructure (same as Fig. 2) - different magnifications. Cooling rate $50 \mathrm{~K} / \mathrm{min}$ to $\mathrm{RT}$.

Fig. 4. Ti grade 2. Carbo-oxidation at $1050^{\circ} \mathrm{C}$ for 20 hours. A) Stereomicroscopy - overview. All surfaces have been hardened - including the internal tread. B to E) Reflected light optical microscopy: Formation of a case consisting of a mixed interstitial compound and diffusion zone in the surface; different magnifications.

Figure 5. Hardness depth profiles for surface hardened Ti grade 2 (treatment shown in Fig. 4). Dotted lines are given to guide the eye (diffusion zone and compound zone). At $700 \mu \mathrm{m}$ the compound zone ends.

Fig. 6. Ti grade 5. Carbo-oxidation at $1000{ }^{\circ} \mathrm{C}$ for 20 hours. A \& B) Formation of a case consisting of a mixed-interstitial compound and a diffusion zone. C) Core microstructure (cooling 50K/min) 


\section{References}

[1] B. Sarma, K.S. Ravi Chandran, "Recent advances in surface hardening of titanium", JOM 63(2) (2011) 85-92

[2] A. Zhecheva, W. Sha, S. Malinov, A. Long, "Enhancing the Microstructure and Properties of Titanium Alloys through Nitriding and other Surface Engineering Methods", Surface and Coatings Technology 200 (2005) 2192-2207

[3] K.N. Strafford, J.M. Towell, "The Interaction of Titanium and Titanium Alloys with Nitrogen at Elevated Temperatures. I. The Kinetics and Mechanism of the Titanium-Nitrogen Reaction", Oxidation of Metals, 10(1) (1976) 41-67

[4] J.-P. Bars, D. David, E. Etchessahar, J. Debuigne, "Titanium $\alpha$-Nitrogen Solid Solution Formed by High Temperature Nitriding: Diffusion of Nitrogen, Hardness and Crystallographic Parameters", Metallurgical Transactions A 14A (1983) 1537-1543

[5] A. Zhecheva, S. Malinov, W. Sha," Microstructure and Microhardness of Gas Nitrided Surface Layers in Ti-8Al-1Mo-1V and Ti-10V-2Fe-3Al Alloys", Surface Engineering 21(4) (2005) 269278.

[6] V.N. Fedirko, T.N. Pogrelyuk, "Kinetics of Nitriding Titanium Alloys at 1173K", Soviet Materials Science 19(6) (1984) 511-513.

[7] L. Liu, F.Ernst, G.M. Michal, A.H. Heuer, "Surface Hardening of Ti Alloys by Gas-Phase Nitridation:Kinetic Control of the Nitrogen Surface Activity", Metallurgical Transactions A 36A (2005) 2429-2434.

[8] A.S.M.A. Haseeb, M.F. Islam, M.O. Alam, S.A.M. Tofail, "Surface Hardening Behavior of Titanium Alloys in Carburization", Titanium Extraction and Processing (1997) 163-173

[9] I.V. Nikonorova, E.L. Gyulikhandanov, " Carburizing Titanium and Cobalt Alloys in Propane with Simultaneous Formation of a Carbon Coating”, Metal Science and Heat Treatment 40(1-2) (1998) 52-53.

[10] Y. Luo, S. Ge, D. Zhang, Q. Wang, H. Liu,” Fretting Wear of Carburized Titanium Alloy Against $\mathrm{ZrO}_{2}$ under Serum Lubrication”, Tribology International 44 (2011) 1471-1475.

[11] C. Liao, Y. He, J. Yang, B. Nan, X. Liu, "Effect of Carburization on Electrochemical Corrosion Behaviours of TiAl Alloy", Materials Science and Engineering B 178 (2013) 449-456.

[12] P.K. Ajikumar, M. Vijayakumar, M. Kamruddin, S. Kalavathi, N. Kumar, T.R. Ravindran, A.K. Tyagi, "Effect of Reactive Gas Composition on the Microstructure, Growth Mechanism and Friction Coefficient of TiC Overlayers", Int. Journal of Refractory Metals and Hard Materials 31 (2012) 62-70. 
[13] J. Stringer, "The Oxidation of Titanium in Oxygen at High Temperatures", Acta Metallurgica 8 (1960) 758-766.

[14] A. Takamura, Trans. "Surface Hardening of Titanium by Oxygen”, JIM 3 (1962) 10-14.

[15] C. Chen, Q. Cao, X. Xu, H. Ma, "Surface Oxygen Diffusion Hardened Titanium Material TC4”, Advanced Materials Research 306-307 (2011) 447-450.

[16] V.M. Fedirko, A.T. Pichuhin, O.H. Luk'uanenko, V.S. Onuferkom, "Interstitial Hardening of the Surface of Titanium by Vacuum Heat Treatment", Materials Science 41(2), 2005.

[17] W. Yan, X.X. Wang, "Surface hardening of titanium by thermal oxidation", Journal of Materials Science 39 (2004) 5583-5585.

[18] Y.Z. Kim, T. Konno, T. Murakami, T. Narushima, C. Ouchi, "Surface Hardening Treatment for Titanium Materials Using Ar-5\%CO Gas in Combination with Post Heat Treatment Under Vacuum“, Materials Transactions 50(12) (2009) 2763-2771.

[19] A.E. Barington, M.S. Jellesen, T.L. Christiansen, "Gaseous Surface Hardening of Titanium Alloys", 29th International Conference on Surface Modification Technologies, 10-12 June 2015, Copenhagen, Denmark, proceedings.

[20] H. Dong, X.Y. Li, "Oxygen Boost Diffusion for the Deep-Case Hardening of Titanium Alloys Materials Science and Engineering”, A280 (2000) 303-310.

[21] J.C. Avelar-Batista, E. Spain, J. Housden, A. Matthews, G.G. Fuentes, "Plasma Nitriding of Ti6Al4V Alloy and AISI M2 Steel Substrates Using DC Glow Discharges Under a Triode Configuration", Surface and Coatings Technology 200 (2005) 1954-1961.

[22] S.L.R. da Silva, L.O. Kerber, L. Amaral, C.A. dos Santos, "X-ray Diffraction Experiments of Plasma-Nitrided Ti-6Al-4V”, Surface and Coatings Technology 116-119 (1999) 342-346.

[23] S. Fukumoto, H. Tsubakino, S. Inoue, L. Liu, M. Terasawa, T. Mitamura, “Surface Modification of Titanium by Nitrogen Ion Implantation" Materials Science and Engineering A 263 (1999) 205-209.

[24] V. Fouquet, L. Pichon, M. Drouet, A. Straboni, "Plasma Assisted Nitridation of Ti-6Al-4V", Applied Surface Science 221 (2004) 248-258.

[25] T. Kim, Y. Park, M. Wey, "Characterization of Ti-6Al-4V Alloy Modified by Plasma Carburizing Process”, Materials Science and Engineering A 361 (2003) 275-280.

[26] V.M. Fedirko, I.M. Pohrelyuk, O.I. Yas'kiv, "Formation of Functional Coatings Based on Interstitial Compounds on Titanium Under the Conditions of Thermodiffusion Saturation", Materials Sciences 42(3) (2006) 299-308 
[27] I. Pohrelyuk, O. Yaskiv, V. Fedirko, "Forming Carbonitride Coatings on Titanium by Thermochemical Treatment with C-N-O-Containing Media” JOM, June (2007), 32-37

[28] H.J. Goldschmidt, “Interstitial Alloys" (1967).

[29] R. Bailey, Y. Sun, "Pack Carburisation of Commercially Pure Titanium with Limited Oxygen Diffusion for Improved Tribological Properties”, Surface and Coatings Technology, 261 (2015), 2834. 
FIG1
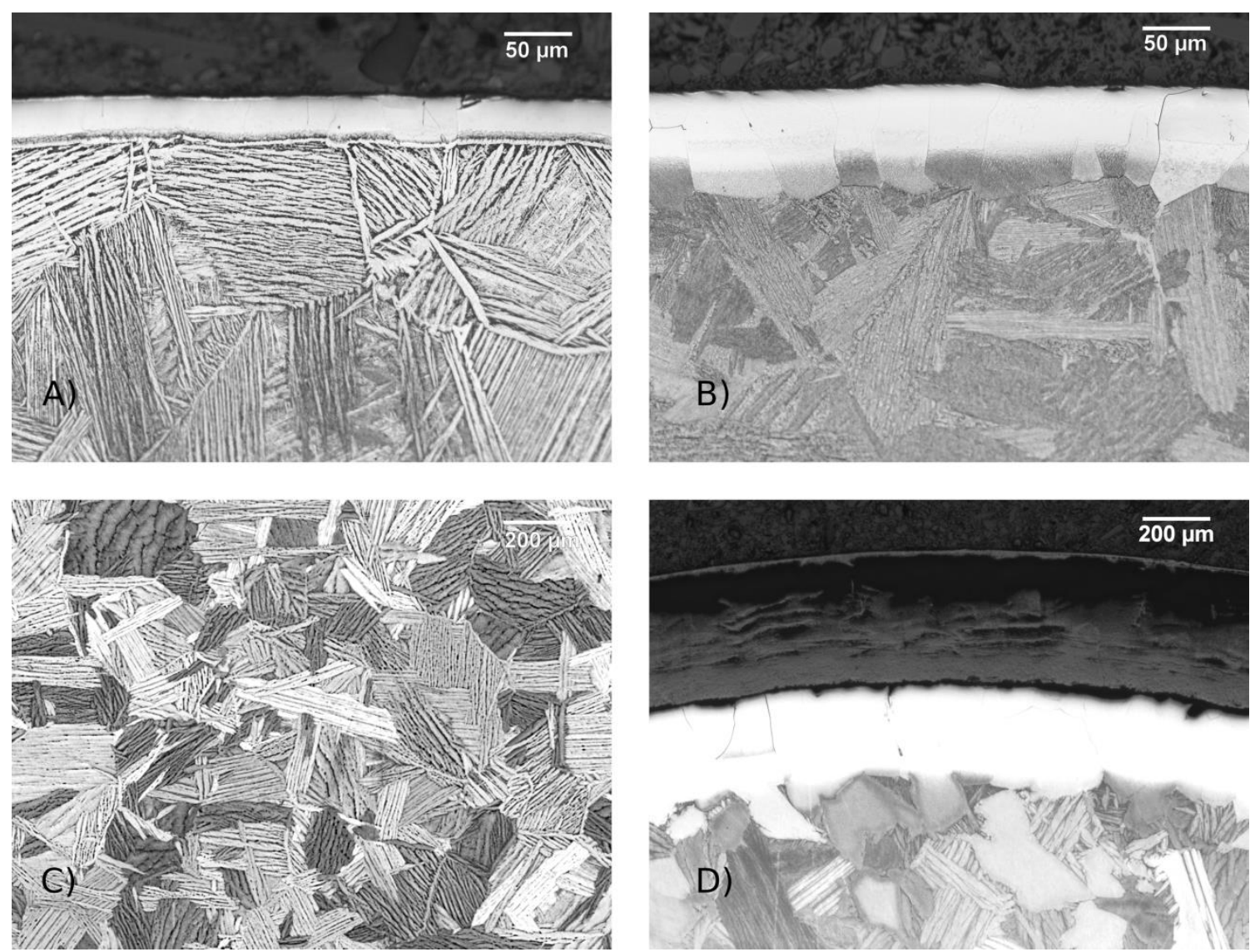

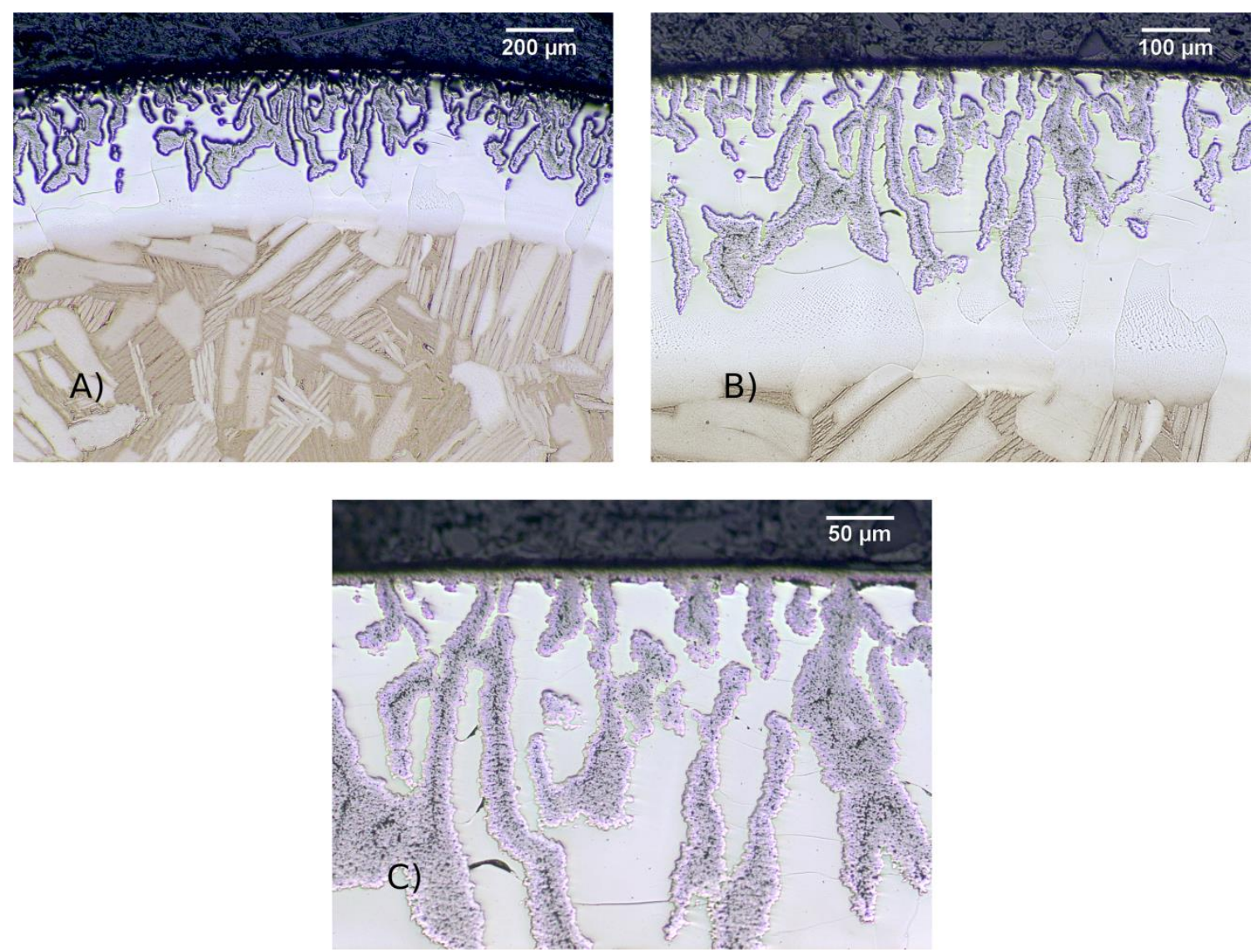
FIG3
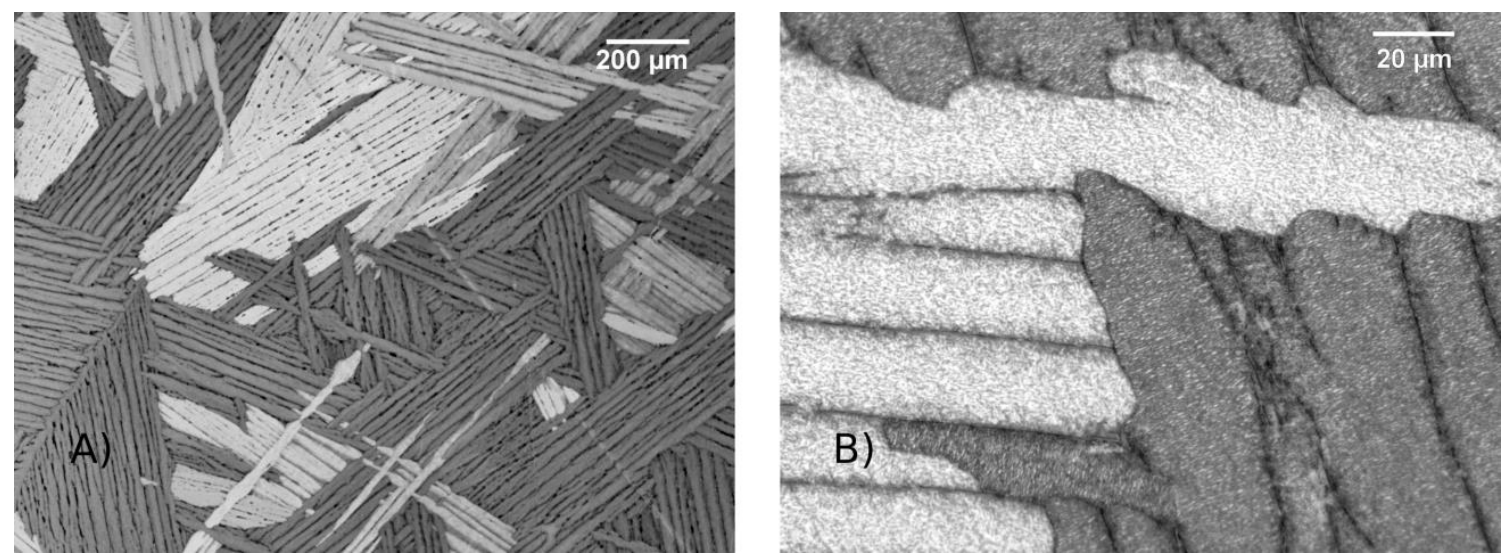
FIG4
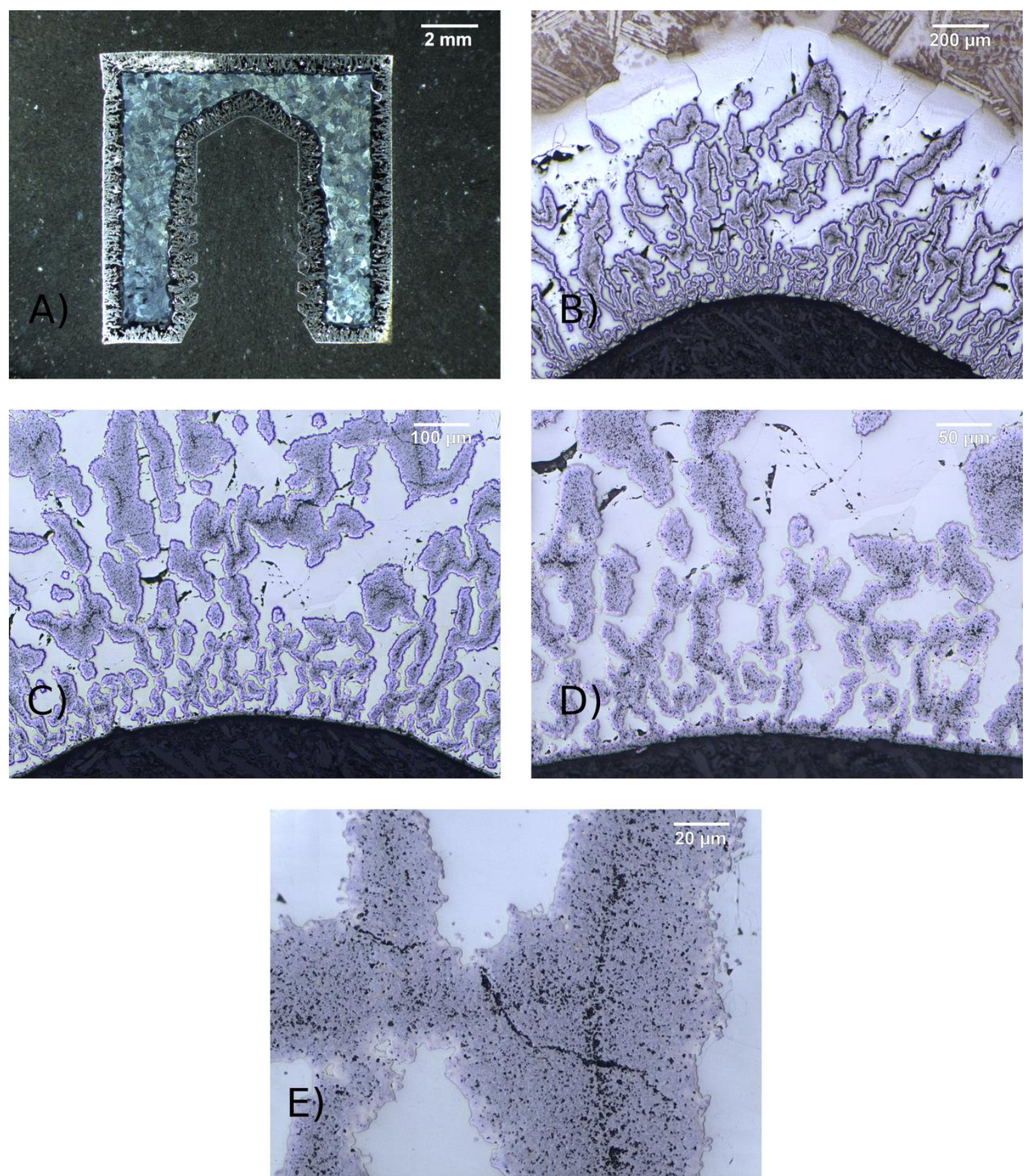
FIG5

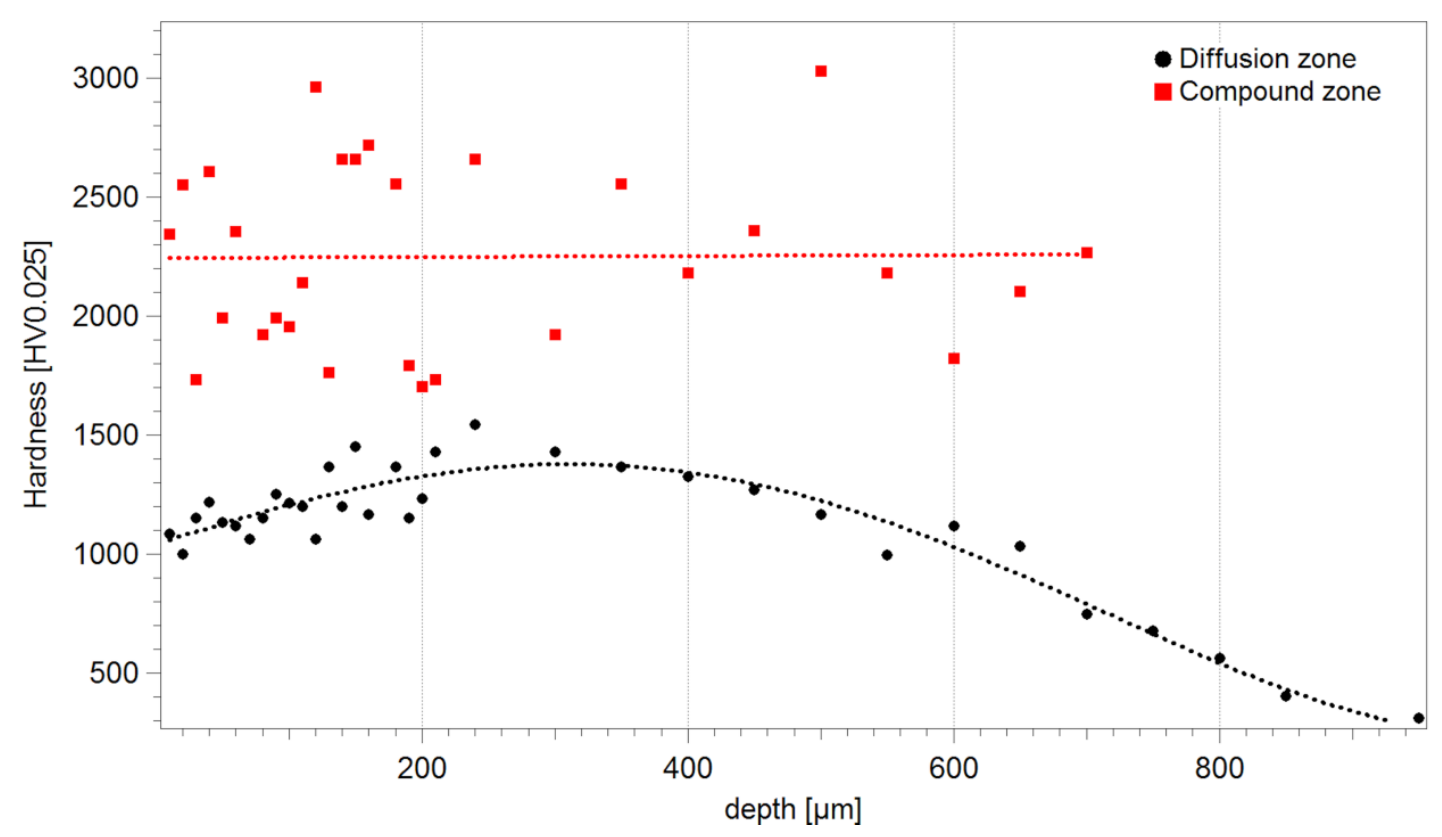



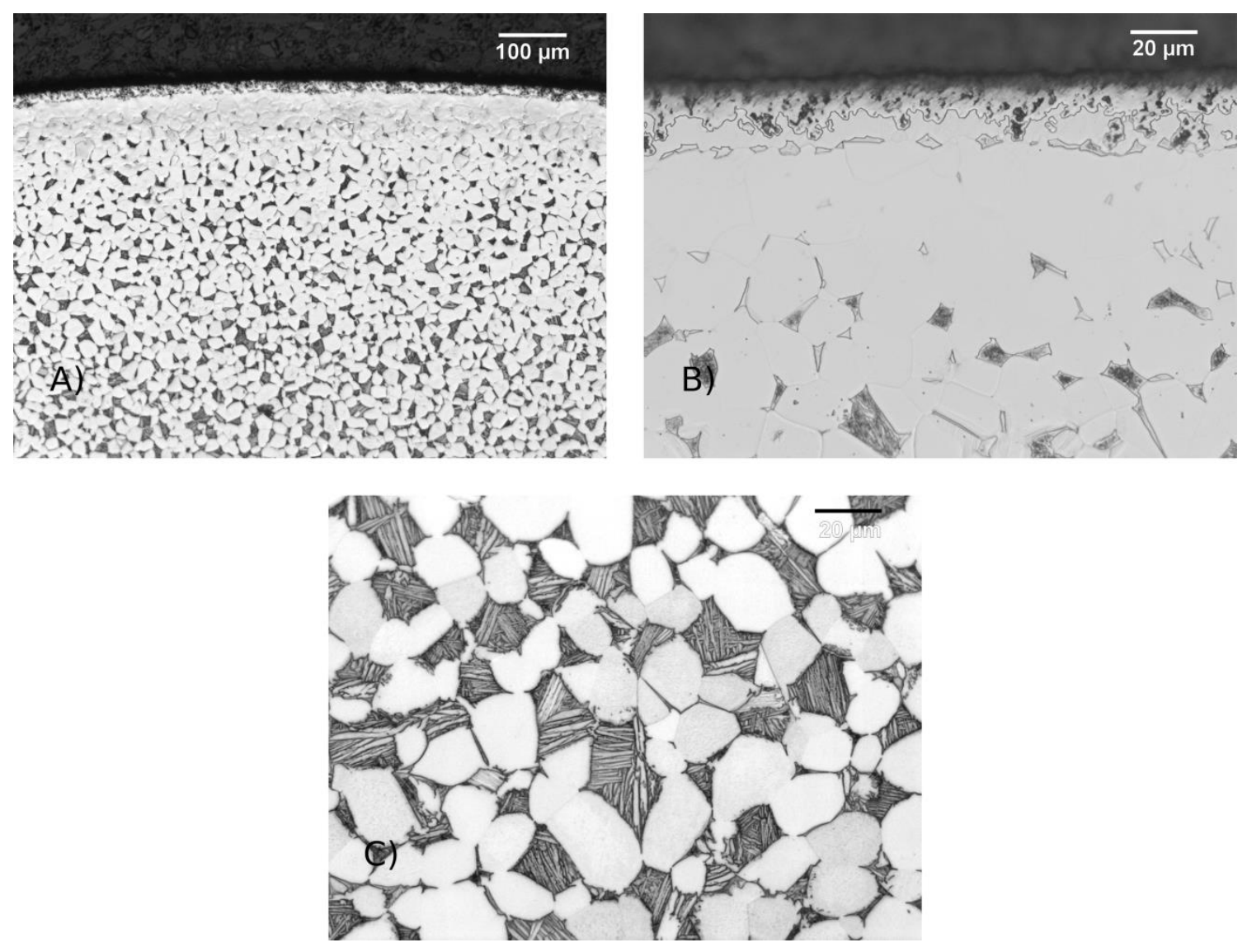